\title{
Type of activity and fitness benefits as moderators of the effect of physical activity on affect in advanced age: a review
}

\author{
Yael Netz
}

Received: 30 July 2008 / Accepted: 6 January 2009 / Published online: 23 January 2009

(C) EGREPA 2009

\begin{abstract}
This study aimed to review studies exploring the effect of physical activity on affect in advanced age with a special focus on the moderating role of fitness improvement and mode of exercise and to examine those studies in relation to the potential mechanisms for explaining the physical activity-affect relationship. Studies were assembled through a computer search of online psychological, medical, and exercise science databases. Randomized controlled studies having as their purpose the examination of physical activity effects on affect, with a mean sample population age of at least 50 years, were included. Thirtynine studies were collated and divided into three groups: those applying aerobic activity, those applying strength training, and those applying non-specific physical activity. The main finding was that aerobic exercise and aerobic fitness do not moderate the effect of physical activity on affect. While fewer than $50 \%$ of the aerobic studies reporting fitness improvement also reported improvement in affect, over $50 \%$ of the strength training studies and of the non-specific exercise studies reported improvement in affect. Theories with a physiological orientation claiming that aerobic fitness is the mediator between physical activity and affect are not supported, whereas theories with a psychological orientation maintaining that alterations in affect are not dependent on physiological alterations do receive support. It is argued that the differentiation between physiologically and psychologically oriented theories is arbitrary. It is recommended that the relationship between
\end{abstract}

\section{Y. Netz $(\bowtie)$}

The Zinman College of Physical Education and Sport Sciences,

Wingate Institute,

42902 Netanya, Israel

e-mail: neyael@wincol.ac.il physical activity and affect be explored further, embracing a psychophysiological perspective in which the psychological and physiological perspectives are complementary.

Keywords Exercise mode - Aerobic fitness ·

Psychophysiological perspective $\cdot$ Old age

\section{Background and rationale}

People are living increasingly longer, and the senior population aged 65 and older has been rising consistently over the past few decades [33]. While many factors, such as health, physical function, and independence, constitute components of quality of life in old age, psychological functioning is of particular significance, as it is crucial in determining the ability to maintain productivity, independence, and an active interaction with the environment [70]. The literature on the relationship between physical activity and psychological functioning in old age is continually expanding. However, while physical activity guidelines for physical fitness in old age are well documented (see [51]), the effect of physical activity on affect is less clear. The present paper focuses on this relationship, examining in particular whether exercise modality and fitness improvement serve as moderators.

\section{Theoretical perspective}

The literature on physical activity and psychological functioning in advanced age generally concentrates upon either cognition or affect (e.g., [1, 70]). Cognitive function is dependent upon the central nervous system, which declines increasingly over the adult life span, bringing in 
its wake attrition in a wide variety of cognitive abilities [64]. Affect, on the other hand, may be altered throughout the life span - not necessarily as a function of the aging process per se but rather as a function of personal adjustment to health or other environmental factors [52]. This difference impacts on the mechanisms explaining the relationship between these dimensions and physical activity and consequently on the modes and doses of physical activity needed to engender the changes. The mechanisms explaining the relationship between physical activity and cognition are based on exercise-induced physiological processes occurring as a result of aerobic activity, which counteracts the decline which occurs during the aging process [28]. On the other hand, the proposed mechanisms explaining the relationship between physical activity and affect include both physiological theories based on changes triggered by aerobic exercise and psychological theories which do not necessarily imply specific modes of physical activity.

Researchers with a physiological orientation argue that physiological changes in cardiovascular function [39], neural hormones [48], endorphins [73], and body temperature [23] are the mechanisms mediating physical activity and affect, and thus specifically prescribed aerobic exercise is required to engender these changes. A noteworthy physiologically oriented theory in exercise science is based on asymmetrical anterior brain activation, which shows that this asymmetry, as measured by an electroencephalogram (EEG), can serve as a biological marker of affect [21]. A series of studies assessing the relationship between frontal asymmetry and exercise in young participants indicated that resting EEG asymmetry predicted postexercise affect, specifically an increase in activated pleasantness, and this appeared to be influenced by aerobic fitness $[60,61]$.

Researchers with a psychological orientation, who view the exercise-affect relationship as an exclusively psychological phenomenon, maintain that alterations in affect are caused by distraction from the stresses of life [3], changes in self-efficacy [5], feelings of mastery [76], and social interaction [42] - things which make people "feel better" [44]. Consequently, the alterations in affect engendered by physical activity are not dependent on physiological alterations and may be achieved by different modes of physical activity at various intensities. Spirduso and Cronin [69] suggested that physical activity can enhance quality of life in the elderly without improving cardiorespiratory status. They postulated that the act of exercising might be beneficial in and of itself. Furthermore, even if alterations in aerobic fitness are achieved, alterations in affect are not necessarily associated with them. Studies reporting improvements in fitness and in well-being in older adults as a result of aerobic exercise found those improvements to be unrelated (e.g., [42]).

\section{Previous reviews}

Quite a few studies have posed the question of whether physical activity alters affect in old age. Not unexpectedly, these studies differ on all possible variables, including mode of exercise, exercise dose, and affective measurements. Quantitative reviews examining exercise modality as a possible moderator of physical activity effect on various aspects of well-being, including affect, have produced conflicting results. One meta-analysis [55] indicated an association between resistance training and reducing depression, while no such association was indicated by those on anxiety [36, 59]. Another more recent meta-analysis [71] indicated that resistance training may be equally effective in reducing depressive symptoms compared to aerobic activity. Two meta-analyses focusing on older populations were also inconsistent with each other in their findings. One reported that strength training had a greater effect size than aerobic exercise on the activity-mood relationship [2], while the other [53] found that aerobic training (followed closely by strength training) was the most beneficial means of altering well-being. Furthermore, in contrast to previous findings of no dependency between physical fitness and well-being improvement [42] or between fitness and a decrease in depression symptoms [71], the meta-analysis by Netz and colleagues did find that improvements in both cardiovascular capacity as well as strength were significant moderators of the relationship between physical activity and well-being.

In addition to their conflicting results, most studies included in previous reviews used aerobic exercise as the treatment modality, causing some inequalities in the comparisons between exercise modalities. For example, in a review assessing the effects of physical activity on depression and anxiety disorders [24], 16 out of 19 studies used aerobic exercise and only three used resistance training. The same trend was evident in the meta-analyses mentioned above focusing on older adults [2,53].

Additionally, previous reviews discussed the relationship between physical activity and different aspects of wellbeing using a broad perspective. They did not focus on intervention studies examining the ability of physical activity to alter affect in old age. Affect is a cornerstone of well-being [70]. In later life, the physical, mental, and social changes that accompany aging bring with them challenges to affective well-being that are above and beyond those routinely experienced by most younger individuals [70]. Not surprisingly, quite a few studies point out the high prevalence of depression in the elderly (e.g., [9]). As people age, they must continually adjust to major challenges, such as declining physical ability and declining health, the loss of loved ones, retirement, reduced income, new social roles, and relocation of physical living 
arrangements [31]. Exploring the potential of physical activity for reducing negative feelings and stimulating positive feelings may contribute to well-being in older age. Similar to previous reviews $[19,55]$, the present review includes both non-clinical and clinically depressed populations. On the other hand, other clinically unique populations such as demented individuals or Parkinson's disease patients were excluded due to a wide range of possible uncontrolled confining variables.

\section{The purpose of the current review}

The purpose of this paper is therefore to review studies exploring the effect of physical activity on affect in advanced age with a special focus on the moderating role of fitness improvement and mode of exercise. Although it is a descriptive review, it may provide an answer to the question of whether improvement in affect depends on improvement in physical fitness (if it does, it is meaningful in terms of determining the exercise dose needed for altering affect) and to the question of whether aerobic activity is superior to strength training or other exercise modes in altering affect in old age. A discussion of these issues can also provide insight into some of the potential mechanisms driving the physical activity-affect relationship. As this review incorporates many recent studies not included in past reviews, it will also re-examine whether aerobic exercise is still dominant as a training modality in studying the effect of physical activity on affect.

\section{Method}

This review adopts a broad definition of both physical activity and affect. Despite the various distinctions between mood, affect, and emotion, most researchers use these terms interchangeably when studying the relationship between affect and physical activity $[2,42]$. Studies reviewed herein were gathered from a computer search of several online psychological, medical, and exercise science databases, scrutinizing the contents of all likely scientific journals and publications as far back as available. Three primary inclusion criteria were adopted: first, the study had to have as its purpose the examination of physical activity effects on affect; second, each study had to include older adults (mean age of at least 50 years old) in its sample population; third, the study had to be a randomized controlled trial.

In terms of the mediating mechanisms proposed for explaining the relationship between physical activity and affect, it is appropriate to differentiate between three groups of studies based on the training modality they apply. While studies using aerobic activity assume that cardiovascular change is the mediating mechanism between activity and the affective component, studies applying resistance exercise assume that strength improvement is the mediating mechanism. On the other hand, studies applying mixed and assorted modalities generally assume that any physical improvement or subjective perception of improvement is the mediating mechanism. Therefore, the studies in this review were divided into three different groups: those applying aerobic activity, those applying strength training, and those applying non-specific physical activity or in some cases mindful activities such as yoga or Tai Chi.

Review of the studies

Seventeen studies were included in the first group, which assessed the effect of aerobic exercise on affect $[10-13,16$, 25-27, 32, 34, 38, 45, 46, 50, 54, 57, 72]. Eleven studies were included in the second group, which examined the effect of strength training on affect [17, 18, 20, 29, 49, 57, $65-68,74]$, and 15 studies on non-specific physical activity or mindful activities such as yoga or Tai Chi were included in the third group $[4,7,8,10,15,16,18,30,40,47,41,56$, $58,75,77]$. One study [57] compared aerobic and resistance training to a control group in reducing depression and thus was included in both the first and second group. Another study [18], which compared resistance training and general exercise to a control group in altering depression and vitality, was included in both the second and third group. Two others $[10,16]$, comparing aerobic exercise and mindful activities to a control group, were included in the first and third group. While the studies within all three groups vary in terms of the study period, the frequency of exercise, and type of the control groups, most of them examined depression as the affective measure.

\section{Studies applying aerobic activity}

Most of these studies (15 out of 17) assessed aerobic fitness (usually VO2max) in addition to the affective measures. Of the 15 studies that reported an increase in aerobic fitness, only five also reported affective improvement $[12,13,32$, $57,72]$, and two $[16,46]$ reported partial improvement in affect(only a selective sub-group of the experimental group improved). An additional four of those 15 studies reported affective improvement in both the experimental aerobic group and in the non-aerobic exercise control group [34, $50,54]$ or in both the aerobic and attention non-exercise control group [45]. These four studies do not support the superiority of aerobic exercise or aerobic fitness in altering affect. Four studies out of the $15[10,11,25,26]$ did not report any affective improvement. Of the two studies which did not assess aerobic fitness, one study reported affective improvement in the aerobic group [38], and the other 
reported improvement in both the aerobic and non-exercise control groups [27], again questioning the ability of aerobic exercise to alter affect.

These findings indicate that fewer than $50 \%$ of the aerobic studies reporting fitness improvement reported improvement in affect as well. Lack of results in the literature is often explained by methodological shortcomings (e.g., [42]). However, the studies reporting fitness improvement but not affect alterations are not inferior methodologically to those reporting affect changes. The fact that they vary in terms of duration, frequency, type of control groups, and other variables provides support for the idea that lack of improvement is not a function of doseresponse variables. For example, Blumenthal et al. [10,11] conducted well-controlled studies of 4 and 14 months, respectively, without conclusive results, as did Emery and Gatz [25] -3 months, Gitlin et al. [26] - 4 months, and McMurdo and Burnett [45] -8 months. A more recent well-designed randomized controlled study is that of Motl et al. [50], which compared alterations in depressive symptoms between aerobic exercise and low-intensity resistance/flexibility training groups following 24 weeks of exercise. This specific study did not report fitness improvement in the aerobic group; however, reports of fitness improvement in this aerobic group were published in previous studies (e.g., [14]). Furthermore, in spite of the finding that the low-intensity resistance/flexibility control group deteriorated slightly in terms of cardiorespiratory fitness [14], a reduction in depressive symptoms following 6 months of intervention was found in both groups-the relatively intensive aerobic group and the low-intensity resistance/flexibility group. Moreover, this reduction was maintained at 12 and 60 months postprogram initiation in both groups.

Some aerobic studies reporting improvement in affect and in fitness as a result of aerobic activity intervention examined their interdependency. While one study [72] reported an association between the two, two other studies assessing home-based exercise $[32,57]$ reported an association between improvement in affect and exercise compliance rather than between improvement in affect and fitness. This may reflect a predisposition of those who choose to be more active to experience positive emotions. This predisposition supports the concept of approach-and-withdrawal behavior controlled by basic neuroanatomical asymmetry in the brain proposed by Davidson [21, 22] in his EEG and emotion studies. To approach or withdraw from a situation is a fundamental adaptive response, with approach behavior being associated with positive affect and withdrawal behavior being related to negative affect. In this framework, baseline measures of asymmetric anterior activation are associated with a propensity to experience positive or negative emotions, given the requisite environmental elicitors [22], in this case physical activity. While greater right-relative-to-left frontal activation is associated with the withdrawal system and negative affect, greater left-relativeto-right activation pertains to the approach system and positive affect [22].

\section{Studies applying strength training}

More interesting and relatively more recent are studies assessing the effect of strength training on affect. While 12 studies from before 2000 were found that employed aerobic training, compared to only five using strength training, from 2000 and onward, strength training and aerobic training modalities were employed in an equal number of studies - five aerobic trainings and five strength trainings. As in the aerobic group, quite a few studies (seven out of 11) assessed strength improvement in addition to pre-post differences in affect. However, while less than $50 \%$ of the aerobic training studies reported changes in affect as a result of the exercise, over $50 \%$ of the strength training studies reported affect alteration following the exercise. Of the seven reporting strength improvement, four also reported improvement in affect $[17,66,68,74]$ and two reported partial improvement [29, 49]. These studies varied in the length of the intervention. For example, while the study of Cassilhas et al. [17] reported improvement after 24 weeks, the Singh et al. [68] study was able to demonstrate improvement after 8 weeks and Tsutsumi et al. [74] after 12 weeks. One study [20] did not report any emotional alterations following 8 weeks of resistance training. Of the four studies which did not assess strength improvement, one study [67] reported alleviation in depression, and another one [65] reported partial improvement in depression. The other two $[18,57] \mathrm{did}$ not observe any affective alteration following 12 and 24 weeks, respectively.

The study by Penninx et al. [57], which compared the effect of aerobic and strength training on depression, deserves special mention. While depression was reduced following aerobic training according to this study, it was not altered following strength training. In contrast, the studies by Singh et al. [66-68], Tsutsumi et al. [74], and Cassilhas et al. [17] were unequivocal in indicating improvement both in strength and in mood and depression. Further, one of the Singh et al. studies [67] reported that the antidepressant effect of exercise was maintained over 20 weeks when laboratory-based supervised exercise was changed to unsupervised patient-directed weight lifting in gym or home settings. Moreover, this alleviating effect was maintained more than 2 years after the start of the intervention. Interestingly, one third of the participants initially assigned to the exercise group were still exercising after 2 years. This, again, may be explained by a disposition 
to exercise by those who gain more pleasure from it due to greater left-relative-to-right brain activation [22].

Studies applying general non-specific physical activity

Only six studies out of the 15 in this group assessed physical measurements in addition to affect: one assessed strength [75]; one mobility, strength, gait velocity, and balance [30]; one strength and gait velocity [7]; one balance and flexibility [56]; one strength, balance, 6-min walk, gait velocity, chair stand, and stair climb [4]; and one 6-min walk, 4-m walk, and chair stand [15]. Five of those six [4, $7,15,30,75]$ reported affective improvements in addition to physiological improvements. However, four of the nine studies which did not assess physical improvement [16, 41, $47,77]$ reported affective improvement, and two of the nine $[8,40]$ reported partial improvements.

Although variability in the studies applying non-specific physical activity is quite high, improvement in affect is generally demonstrated in more than $50 \%$ of them. As is the case in the other two groups, the variability in the studies reporting affective alterations in terms of the length of the intervention is quite high, including studies lasting 6 [47], 10 [4], 12 [41, 77], 16 [15, 16, 30], 24 weeks [7], and a year [75]. One of the two studies comparing mindful activity (yoga) to aerobic activity found no alterations in either group [10], and the other [16] reported partial improvement in both the mindful (Tai chi) and the aerobic group. The findings of the third non-specific group certainly calls into question the superiority of aerobic exercise over other types of exercise, as well as the dependency of improvement in affect on improvement in aerobic fitness.

\section{Comparison with previous reviews}

Consequently, the findings of the present review are similar to past narrative reviews questioning the benefit of cardiorespiratory fitness for reducing symptoms of depression [24] or for enhancing quality of life (including affect) in advanced age [69]. They also support a previous review reporting no association between improvement in fitness and improvement in well-being among older adults as a result of aerobic exercise [42]. The present findings are also in-line with two previous quantitative reviews examining the effect of physical activity on mood [2] and on general well-being including mood [53] in older adults. While the Arent et al. review did not find dependency between fitness and mood improvement, the Netz et al. did find that fitness was a moderator. However, improvement in strength and functional capacity was just as much a moderator as cardiovascular fitness.

This review questions not only the superiority of aerobic exercise over strength training but also the superiority of any type of exercise mode in improving affect in advanced age. Many of the studies screened for this review applying strength training and non-specific exercise modes were able to demonstrate improvement in affect. This may explain, to some extent, the inconsistency found in previous quantitative analyses. While one [2] reported a greater effect size for strength training than for aerobic training in altering mood, the other [53] found that aerobic training was most beneficial in altering well-being, with strength training coming in a close second.

\section{Limitations of the present review}

While this review is quite exhaustive in that it incorporates the vast majority of studies in the area, the shortcomings of such a narrative review are obvious. Comparing aggregates of studies which apply different designs and interventions and examine different populations is problematic. Furthermore, the single study that compared aerobic exercise to strength training in the same population did find that aerobic exercise was superior to strength training [57]. However, the fact that a greater proportion of successful to unsuccessful studies (in terms of demonstrating alterations in affect as a result of exercise) was in favor of strength training and non-specific exercise as compared to aerobic exercise does question the superiority of aerobic exercise over other modes of exercise.

It may be argued that clinical and non-clinical populations should be investigated separately, on the grounds that the mechanisms mediating physical activity and affect are different for the two types of populations. In addition, it has been shown that clinical populations are more sensitive to affect alterations than non-clinical [19]. Indeed, some metaanalyses focused on clinical populations [19, 37], while the Netz et al. [53] meta-analysis studied non-clinical populations only. However, the moderating effect of the training modality or fitness improvement is no less questionable in clinical than in non-clinical populations. For example, while Blumenthal et al. $[12,13]$ indicated that aerobic exercise was very useful in alleviating depressive symptoms in clinically depressed individuals (in comparison to medication), Singh et al. [66-68] were able to demonstrate that strength training was also efficient in reducing depression in clinical populations. Yet, Brenes et al. [15] showed that a combination of the two was also useful for the treatment of depression. The superiority of aerobic exercise over other modes of exercise is therefore questionable in clinical as well as in non-clinical populations.

A theoretical perspective

From a theoretical perspective, it seems that the present review supports the psychologically oriented theories, 
which do not imply any specific mode of physical activity but rather ascribe the mediating effect of physical activity on affect to its role in distracting from the stresses of life [3], as well as to changes in self-efficacy [5], feelings of mastery [76], and social interaction [42]. It is possible that feeling of mastery and elevated physical self-esteem moderate people's affective reactions, as was demonstrated in some studies (e.g., [44, 50]) and also reduce anxiety levels, possibly by dampening biological stress reactions such as cortisol concentrations [6, 63]. Furthermore, for older adults, whose self-efficacy may be deteriorating along with their functional abilities, physical activity may provide a mastery experience that leads to increased self-efficacy [43], which in turn leads to improved psychological wellbeing [42]. The increase in self-efficacy and feeling of mastery may therefore be a mediating mechanism between physical activities and affect, especially in older adults. This increase in self-efficacy and feeling of mastery, however, is not necessarily a function of improved cardiovascular fitness; it may also be a function of increased strength or a function of simply participating in the activities, as proposed by Spirduso and Cronin [69].

While the physiologically oriented theories implying that changes in aerobic fitness are necessary for altering affect are not supported in the present review, this does not mean that the mechanisms they propose do not mediate physical activity and affect. Alterations in neural hormones [48], endorphins [73], body temperature [23], and frontal asymmetry [21] may also be the mediating mechanisms. However, these mechanisms have so far only been proven in relation to aerobic exercise and aerobic fitness. Furthermore, the differentiation between physiologically and psychologically oriented theories is somewhat arbitrary. With the tremendous increase of interest in the linkage between brain functioning, affect, and behavior [21, 22], it is clear that rather than a dualistic reductionistic approach, a potentially more informative approach is needed that embraces mind-body unity, an approach captured in the psychophysiological perspective. Psychophysiology, as a field of study, involves the examination and viewing of psychological phenomena (cognitive, affective, behavioral) as related to and revealed through physiological principles and events. Psychological and physiological perspectives are believed to be complementary. Essentially, the point is that considering both physiological and psychological perspectives reduces the chances of error related to operationalization, measurement, and inference [62]. Perhaps affective responses to low-intensity activities are not related to measures of peripheral physiological activity, either because those measures examined to date (e.g., heart rate, oxygen uptake) have been irrelevant or have been influenced by a restriction of range or because the most relevant physiological measures are central and not peripheral [62].
From the existing research, however, it is apparent that the psychological effect of exercise in advanced age is explained for cognition and affect through different channels. While the cognitive effect is clearly moderated by aerobic activity and aerobic fitness [28], training modality and fitness improvement are not moderators of the physical activity effect on affect. This may only indicate that further investigations are needed to examine possible psychophysiological mechanisms mediating physical activity and affect.

\section{Reservations in terms of practical implications}

Viewed in practical terms, the existing body of information implies that, in general, physical activity in advanced age is recommended for altering affect but without any specific recommendation for training modality or dose of exercise. However, the existing research suffers from some limitations. One is the lack of studies focusing on positive affect. Most of them concentrate on negative affect, usually depression. Reducing bad mood and increasing good mood should be viewed as distinct and independent dimensions, not just opposite ends of a continuum [35]. This shortcoming is reinforced by the study of Kunzmann et al. showing that it is positive affect that declines steadily throughout aging, while negative affects remain the same or even decreases with age. As was suggested by Arent et al. [2], physical activity could be much more appealing to the elderly if they were told it could make them feel "good" rather than simply "less miserable."

Another problematic issue in terms of practical implications is the disposition of some people to be physically active and of others to avoid exercise. All studies are based on volunteers. As was proposed by Davidson [22], to approach or withdraw from a situation is a fundamental adaptive response, with approach behavior being associated with positive affect and withdrawal behavior with negative affect. This disposition has a physiological base reflecting neuron-anatomical asymmetry in the frontal lobes of the brain. Perhaps those who volunteer to participate in exercise studies are people who have a propensity to experience pleasure and thus have a positive approach to this activity. If this is the case, understanding the wellevidenced advantages of physical activity is not sufficient, and the promotion of physical activity will be effective only for those who enjoy exercise. Perhaps there should be more types of exercise recommended, so that people will be able to choose the type that they perceive will be pleasurable to them. It should be relatively easy to offer activities for those who find satisfaction merely in being active. Those people would most likely seek out the activities that give them pleasure. However, health and exercise promoters should offer physical activity incentives that also attract people 
who do not enjoy being physically active. For example, outdoor activities may be enjoyable for some people and group physical activities may provide pleasure to others. Yet for those who avoid both options, walking as a means of saving transportation expenses may also serve as an incentive. In other words, "packaging" exercise is also important.

\section{Summary and conclusions}

The purpose of the present review was to examine whether improvement in affect depends on improvement in physical fitness, which reflects exercise dose, and to explore whether aerobic activity, used most often as an exercise modality for altering affect, is superior to other training modalities in altering affect in old age. The main finding of this descriptive analysis is that neither improved fitness nor exercise modality serve as moderators of physical activity effect on affect. While quite a few studies have generally shown the potential of physical activity to alter affect, more studies are needed to understand the mechanisms mediating this effect. Rather than examining the link between physical activity and affect in a dualistic approach, differentiating between physiological and psychological mechanisms, it is recommended that a unified psychophysiological approach be embraced. More studies are also needed to investigate the moderating effect of exercise dose-response, as well as that of exercise modality in the exercise-affect relationship. As most existing studies examine the potential of physical activity in ameliorating negative feelings, such as depression, it is essential to assess the ability of physical activity to stimulate positive feelings as well, such as happiness and optimism.

\section{References}

1. American College of Sports Medicine (ACSM) (1998) Exercise and physical activity for older adults. Med Sci Sports Exerc 30:992-1008. doi:10.1097/00005768-199806000-00033

2. Arent SM, Landers DM, Etnier JL (2000) The effects of exercise on mood in older adults: a meta-analytic review. J Aging Phys Act 8:407-430

3. Bahrke MS, Morgan WP (1978) Anxiety reduction following exercise and meditation. Cognit Ther Res 2:323-333. doi:10.1007/ BF01172650

4. Baker MK, Kennedy DJ, Bohle PL, Campbell DS, Knapman L, Grady J et al (2007) Efficacy and feasibility of a novel tri-modal robust exercise prescription in a retirement community: a randomized, controlled trial. J Am Geriatr Soc 55:1-10. doi:10.1111/ j.1532-5415.2006.01031.x

5. Bandura A (1977) Self-efficacy: toward a unifying theory of behavioral change. Psychol Rev 84:191-215. doi:10.1037/0033295X.84.2.191
6. Bandura A (1991) Self-efficacy mechanism in physiological activation and health promoting behavior. In: Madden $\mathrm{J}$ (ed) Neurobiology of learning, emotion, and affect. Raven, New York, pp 229-269

7. Bastone ADC, Filho WJ (2004) Effect of an exercise program on functional performance of institutionalized elderly. J Rehabil Res Dev 41:659-668. doi:10.1682/JRRD.2003.01.0014

8. Bennett J, Carmack MA, Gardner VJ (1982) The effect of a program of physical exercise on depression in older adults. Phys Educator 39:21-24

9. Blazer DG (1994) Epidemiology of late-life depression. In: Schneider LS, Reynolds CF, Lebowitz BD, Friedhoff AI (eds) Diagnosis and treatment of depression in late life. American Psychiatric, Washington, DC, pp 9-19

10. Blumenthal JA, Emery CF, Madden DJ, George LK, Coleman RE, Riddle MW et al (1989) Cardiovascular and behavioral effects of aerobic exercise training in healthy older men and women. J Gerontol 44:147-157

11. Blumenthal JA, Emery CF, Madden DJ, Schneibolk S, WalshRiddle M, George LK et al (1991) Long-term effects of exercise on psychological functioning in older men and women. J Gerontol 46:352-361

12. Blumenthal JA, Babyak MC, Moore KA, Craighead WE, Herman S, Khatri $\mathrm{P}$ et al (1999) Effects of exercise training on older patients with major depression. Arch Intern Med 159:2349-2356. doi:10.1001/archinte.159.19.2349

13. Blumenthal JA, Babyak MA, Doraiswamy PM, Watkins L, Hoffman BM, Barbour KA et al (2007) Exercise and pharmacotherapy in the treatment of major depressive disorder. Psychosom Med 69:587-596. doi:10.1097/PSY.0b013e318148c19a

14. Boileau RA, McAuley E, Demetriou D, Devabhaktuni NK, Dykstra GL, Katula J et al (1999) Aerobic exercise training and cardiorespiratory fitness in older adults: a randomized control trial. J Aging Phys Act 7:374-385

15. Brenes GA, Williamson JD, Messier SP, Rejeski WJ, Pahor M, Ip E et al (2007) Treatment of minor depression in older adults: a pilot study comparing sertraline and exercise. Aging Ment Health 11:61-68. doi:10.1080/13607860600736372

16. Brown DR, Wang Y, Ward A, Ebbeling CB, Fortlage L, Puleo E et al (1995) Chronic psychological effects of exercise and exercise plus cognitive strategies. Med Sci Sports Exerc 27:765-775. doi:10.1249/00005768-199505000-00021

17. Cassilhas RC, Viana VA, Grassmann V, Santos RT, Santos R, Tufik $S$ et al (2007) The impact of resistance exercise on the cognitive function of the elderly. Med Sci Sports Exerc 39:14011407. doi:10.1249/mss.0b013e318060111f

18. Chin A, Paw MJM, Van Poppel MNM, Twisk JWR, van Mechelen W (2004) Effects of resistance and all-round, functional training on quality of life, vitality and depression of older adults living in long-term care facilities: a 'randomized' controlled trial. BioMedical Central 4:5

19. Craft LL, Landers DM (1998) The effect of exercise on clinical depression and depression resulting from mental illness: a metaanalysis. J Sport Exerc Psychol 20:339-357

20. Damush TM, Damush JG (1999) The effect of strength training on strength and health-related quality of life in older adult women. Gerontologist 39:705-710

21. Davidson RJ (1992) Anterior cerebral asymmetry and the nature of emotion. Brain Cogn 20:125-151. doi:10.1016/0278-2626(92) 90065-T

22. Davidson RJ (1993) The neuropsychology of emotion and affective style. In: Lewis M, Haviland JM (eds) Handbook of emotions. Guilford, New York, pp 143-154

23. De Vries HA, Simard CP, Wiswell RA, Heckathorn E, Carabetta $\mathrm{V}$ (1982) Fusimotor system involvement in the tranquilizer effect of exercise. Am J Phys Med 61:111-122 
24. Dunn AL, Trivedi MH, O’Neal HA (2001) Physical activity doseresponse effects on outcomes of depression and anxiety. Med Sci Sports Exerc 33:S587-S597. doi:10.1097/00005768-20010600100027

25. Emery CF, Gatz M (1990) Psychological and cognitive effects of an exercise program for community-residing older adults. Gerontologist 30:184-188

26. Gitlin LN, Lawton MP, Windsor-Landsberg LA, Kleban MH, Sands LP, Posner J (1992) In search of psychological benefits. J Aging Health 4:174-192. doi:10.1177/089826439200400202

27. Hassmen P, Koivula N (1997) Mood, physical working capacity and cognitive performance in the elderly as related to physical activity. Aging Clin Exp Res 9:136-142

28. Hillman CH, Erickson KI, Kramer AF (2008) Be smart, exercise your heart: exercise effects on brain and cognition. Nat Rev Neurosci 9:58-65. doi:10.1038/nrn2298

29. Jette AM, Harris BA, Sleeper L, Lachman ME, Heislein D, Giorgetti $M$ et al (1996) A home-based exercise program for nondisabled older adults. J Am Geriatr Soc 44:644-649

30. Johnson CSJ, Myers AM, Scholey LM, Cyarto EV, Ecclestone NA (2003) Outcome evaluation of the Canadian Centre for Activity and Aging's Home Support Exercise Program for older adults. J Aging Phys Act 11:408-424

31. Kimmel DC (1990) Adulthood and aging - an interdisciplinary, developmental view. Wiley, New York

32. King AC, Taylor CB, Haskell WL (1993) Effects of differing intensities and formats of 12 months of exercise training on psychological outcomes in older adults. Health Psychol 12:292300. doi:10.1037/0278-6133.12.4.292

33. Kinsella K, Velkoff VA (2001) An aging world: 2001 (US Census Bureau Series P95/01-1). US Government Printing Office, Washington, DC

34. Kohut ML, McCann DA, Russell DW, Konopka DN, Cunnick JE, Franke WD et al (2006) Aerobic exercise, but not flexibility/ resistance exercise, reduces serum IL-18, CRP, and IL-6 independent of b-blockers, BMI, and psychosocial factors in older adults. Brain Behav Immun 20:201-209. doi:10.1016/j.bbi.2005.12.002

35. Kunzmann U, Little TD, Smith J (2000) Is age-relates stability of subjective well-being a paradox? Cross-sectional and longitudinal evidence from the Berlin aging study. Psychol Aging 15:511-526. doi:10.1037/0882-7974.15.3.511

36. Landers DM, Petruzzello S (1994) Physical activity, fitness, and anxiety. In: Bouchard C, Shephard RJ, Stevens T (eds) Physical activity, fitness, and health. Human Kinetics, Champaign, pp 868 882

37. Lawlor DA, Hopker SW (2001) The effectiveness of exercise as an intervention in the management of depression: systematic review and meta-regression analysis of randomised controlled trials. BMJ 31:763-767. doi:10.1136/bmj.322.7289.763

38. Li F, Harmer P, Wilson NL, Fisher KJ (2003) Health benefits of cobblestone-mat walking: preliminary findings. J Aging Phys Act 11:487-501

39. Martinsen EW, Medhus A, Sandvik L (1985) Effects of aerobic exercise on depression: a controlled study. BMJ 291:109

40. Mather AS, Rodriguez C, Guthrie MF, McHarg AM, Reid IC, McMurdo MET (2002) Effects of exercise on depressive symptoms in order adults with poorly responsive depressive disorder. Br J Psychiatry 180:411-415. doi:10.1192/bjp.180.5.411

41. Matsouka O, Kabitsis C, Harahousou Y, Trigonis I (2005) Mood alterations following an indoor and outdoor exercise program in healthy elderly women. Percept Mot Skills 100:707-715. doi:10.2466/PMS.100.3.707-715

42. McAuley E, Rudolph D (1995) Physical activity, aging, and psychological well-being. J Aging Phys Act 3:67-96

43. McAuley E, Shaffer S, Rudolph D (1995) Self-efficacy and affective responses to exercise testing in older males. Int $J$
Aging Hum Dev 41:13-27. doi:10.2190/KAK1-01XJ-CLBLT1EJ

44. McAuley E, Katula J, Mihalko SL, Blissmer B, Duncan TE, Pena $M$ et al (1999) Mode of physical activity and self-efficacy in older adults: a latent growth curve analysis. J Gerontol Psychol Sci Sociol Sci 54B:283-292

45. McMurdo ME, Burnett L (1992) Randomized controlled trial of exercise in the elderly. Gerontology 38:292-298

46. McNeil JK, LeBlanc EM, Joyner M (1991) The effect of exercise on depressive symptoms in the moderately depressed elderly. Psychol Aging 6:487-488. doi:10.1037/0882-7974.6.3.487

47. Means KM, O'Sullivan PS, Rodell DE (2003) Psychological effects of an exercise program in older people who fall. J Rehabil Res Dev 40:49-58. doi:10.1682/JRRD.2003.01.0049

48. Meeusen R (2006) Physical activity and neurotransmitter release. In: Acevedo EO, Ekkekakis P (eds) Psychobiology of physical activity. Human Kinetics, Champaign, pp 129-143

49. Mihalko SL, McAuley E (1996) Strength training effects on subjective well-being and physical function in the elderly. J Aging Phys Act 4:56-68

50. Motl RW, Konopack JF, McAuley E, Elavsky S, Jerome GJ, Marquez DX (2005) Depressive symptoms among older adults: long-term reduction after a physical activity intervention. J Behav Med 28:385-394. doi:10.1007/s10865-005-9005-5

51. Nelson ME, Rejeski WJ, Blair SN, Duncan PW, Judge JO, King AC et al (2007) Physical activity and public health in older adults: recommendation from the American College of Sports Medicine and the American Heart Association. Med Sci Sports Exerc 39:1435-1445. doi:10.1249/mss.0b013e3180616aa2

52. Netz Y (2007) Physical activity and three dimensions of psychological functioning in advanced age: cognition, affect, and self-perception. In: Tenenbaum G, Eklund RC (eds) Handbook of sport psychology. 3rd edn. Wiley, Hoboken, pp 492-508

53. Netz Y, Wu MJ, Becker BJ, Tenenbaum G (2005) Physical activity and psychological well-being in advanced age: a metaanalysis of intervention studies. Psychol Aging 20:272-284. doi:10.1037/0882-7974.20.2.272

54. Nieman DC, Warren BJ, Dotson RG, Butterworth DE, Henson D (1993) Physical activity, psychological well-being, and mood state in elderly women. J Aging Phys Act 1:22-33

55. North TC, McCullagh P, Tran ZV (1990) Effect of exercise on depression. Exerc Sport Sci Rev 18:379-415. doi:10.1249/ 00003677-199001000-00016

56. Oken BS, Zajdel D, Kishiyama S, Flegal K, Dehen C, Haas M et al (2006) Randomized, controlled, six-month trial of yoga in healthy seniors: effects on cognition and quality of life. Altern Ther Health Med 12:40-47

57. Penninx BWJH, Rejeski WJ, Pandya J, Miller ME, Di Bari M, Applegate WB et al (2002) Exercise and depressive symptoms: a comparison of aerobic and resistance exercise effects on emotional and physical function in older persons with high and low depressive symptomatology. J Gerontol Psychol Sci 57B:124132

58. Perri S, Templer DI (1985) The effects of an aerobic exercise program on psychological variables in older adults. Int J Aging Hum Dev 20:167-171. doi:10.2190/A6AB-MBN1-G8HV-258H

59. Petruzzello SJ, Landers DM, Hatfield BD, Kubitz KA, Salazar W (1991) A meta-analysis on the anxiety-reducing effects of acute and chronic exercise outcomes and mechanisms. Sports Med 11:143-182. doi:10.2165/00007256-199111030-00002

60. Petruzzello SJ, Hall EE, Ekkekakis P (1999) Regional brain activation as a biological marker of affective responsivity to maximal exercise. Med Sci Sports Exerc 31:S174 Abstractdoi:10.1097/00005768-199905001-00770

61. Petruzzello SJ, Hall EE, Ekkekakis P (2001) Regional brain activation as a biological marker of responsivity to acute exercise: 
influence of fitness. Psychophysiology 38:99-106. doi:10.1111/ 1469-8986.3810099

62. Petruzzello SJ, Ekkekakis P, Hall EE (2006) Physical activity, affect, and electroencephalogram studies. In: Acevedo EO, Ekkekakis P (eds) Psychobiology of physical activity. Human Kinetics, Champaign, pp 111-128

63. Rudolph DL, McAuley E (1995) Self-efficacy and salivary cortisol responses to acute exercise in physically active and less active adults. J Sport Exerc Psychol 17:206-213

64. Salthouse TA, Siedlecki KL (2007) Efficiency of route selection as a function of adult age. Brain Cogn 63:279-286. doi:10.1016/j. bandc. 2006.09 .006

65. Sims J, Hill K, Davidson S, Gunn J, Huang N (2006) Exploring the feasibility of a community-based strength training program for older people with depressive symptoms and its impact on depressive symptoms. BioMedical Central 6:18

66. Singh NA, Clements KM, Fiatarone MA (1997) A randomized controlled trial of progressive resistance training in depressed elders. J Gerontol Med Sci 52A:M27-M35

67. Singh NA, Clements KM, Singh MA (2001) The efficacy of exercise as a long-term antidepressant in elderly subjects. A randomized controlled trial. J Gerontol Med Sci 56A:M497-M504

68. Singh NA, Stavrinos TM, Scarbek Y, Galambos G, Liber C, Singh MAF (2005) A randomized controlled trial of high versus low intensity weight training versus general practitioner care for clinical depression in older adults. J Gerontol Med Sci 60A: M768-M776

69. Spirduso W, Cronin L (2001) Exercise dose-response effects on quality of life and independent living in older adults. Med Sci
Sports Exerc 33:S598-S608. doi:10.1097/00005768-20010600100028

70. Spirduso WW, Francis KL, MacRae PG (2004) Physical dimensions of aging, 2nd edn. Human Kinetics, Champaign

71. Stathopoulou G, Powers MB, Berry AC, Smits JAJ, Otto MW (2006) Exercise interventions for mental health: a quantitative and qualitative review. Clin Psychol Sci Pract 13:179-193. doi:10.1111/ j.1468-2850.2006.00021.x

72. Swoap RA, Norvell N, Graves JE, Pollock ML (1994) High versus moderate intensity aerobic exercise in older adults: psychological and physiological effects. J Aging Phys Act 2:293-303

73. Thoren P, Floras JS, Hoffman P, Seals DR (1990) Endorphins and exercise: physiological mechanisms and clinical implications. Med Sci Sports Exerc 22:417-428

74. Tsutsumi T, Don BM, Zaichkowsky LD, Taknaka K, Oka K, Ohno T (1998) Comparison of high and moderate intensity of strength training on mood and anxiety in older adults. Percept Mot Skills 87:1003-1011

75. Williams P, Lord SR (1997) Effects of group exercise on cognitive functioning and mood in older women. Aust N Z J Public Health 21:45-52. doi:10.1111/j.1467-842X.1997.tb01653.x

76. Wolinsky FD, Stump TE, Clark DO (1995) Antecedents and consequences of physical activity and exercise among older adults. Gerontologist 35:451-462

77. Yu DSF, Lee DTF, Woo J, Hui E (2007) Non-pharmacological interventions on older people with heart failure: effects of exercise training and relaxation therapy. Gerontology 53:74-81. doi:10.1159/ 000096427 